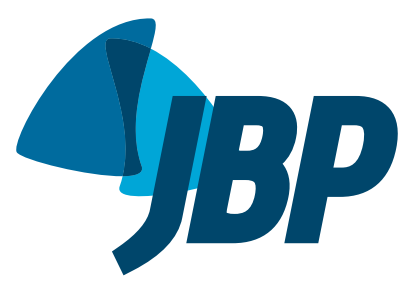

1. Departamento de Cirurgia, Faculdade de Medicina de Botucatu, Universidade Estadual Paulista - UNESP Botucatu (SP) Brasil.

2. Programa de Pós-Graduação em Medicina, Faculdade de Medicina de Botucatu, Universidade Estadual Paulista - UNESP _ Botucatu (SP) Brasil.

a. (iD http://orcid.org/0000-0002-3400-2309

b. iD http://orcid.org/0000-0001-7677-8124

c. (iD http://orcid.org/0000-0003-2330-9337

Submitted: 24 November 2017 Accepted: 26 March 2018.

Study carried out in the Departamento de Cirurgia, Faculdade de Medicina de Botucatu, Universidade Estadual Paulista - UNESP - Botucatu (SP) Brasil.

\section{Mitomycin C in the endoscopic treatment of tracheal stenosis: a prospective cohort study}

\author{
Daniele Cristina Cataneo, ${ }^{1, a}$, Aglaia Moreira Garcia Ximenes 2 ,b, \\ Antônio José Maria Cataneo ${ }^{1, c}$
}

\begin{abstract}
Objective: To evaluate the efficacy of mitomycin $C(M M C)$ in the endoscopic treatment of tracheal stenosis. Methods: Patients with laryngotracheal, tracheal, or tracheobronchial stenosis were treated with dilation and topical MMC. The inclusion criteria were as follows: being ineligible for surgery (for medical reasons) at the time of evaluation; membranous stenosis responding well to dilation; and postoperative stenosis at the anastomosis site. Etiology of stenosis and indication for treatment with MMC, as well as site, length, and percentage of stenosis, together with presence of tracheostomy and duration of follow-up, were analyzed. The outcomes evaluated were symptom-free interval $\geq 12$ months, number of dilations with topical application of MMC, and complications. Results: Twenty-two patients (15 men and 7 women) were treated between 2003 and 2010. Stenosis was due to endotracheal intubation in 15 patients and surgery in 8. Pure tracheal stenosis was encountered in 13 patients, subglottic stenosis was encountered in 4, tracheobronchial stenosis was encountered in 3 , and complex stenosis was encountered in 2 . The length of stenosis ranged from $0.5 \mathrm{~cm}$ to $2.5 \mathrm{~cm}$, and the percentage of stenosis ranged from $40 \%$ to $100 \%$. Nine patients had undergone tracheostomy and had a Montgomery T-tube in situ. Treatment was successful in 14 patients, who remained free of symptoms for at least 12 months. The number of topical applications of MMC ranged from 1 to 5 , and complications included fungal infection, keloid scarring, granuloma, and mediastinal emphysema. Conclusions: MMC appears to be effective in the endoscopic treatment of tracheal stenosis.
\end{abstract}

Keywords: Tracheal stenosis; Mitomycin; Endoscopy.

\section{INTRODUCTION}

Tracheal stenosis was first described in 1880 by MacEwen in patients undergoing endotracheal intubation. ${ }^{(1)}$ In 1886, Colles described it in patients with diphtheria treated with tracheostomy. (2) As a consequence of the introduction of advanced life support in the intensive care setting in the early 1950 s, endotracheal intubation became more common, as did cases of tracheal injury secondary to trauma. In the mid-20th century, tracheal stenosis was treated with dilation, a form of treatment that allowed weaning from tracheal intubation in many cases. However, advances in surgical techniques made tracheal resection the treatment of choice for tracheal stenosis. Nevertheless, the treatment of inoperable tracheal stenosis remains a challenge; new endoscopic treatment techniques have been proposed, with good results. ${ }^{(3)}$ Endoscopic procedures can therefore serve as a bridge to surgical treatment, but they can also be a definitive treatment for many patients, including those who are potential surgical candidates, with success rates ranging from $32 \%$ to $66 \%$. $^{(4)}$

Topical substances such as steroids, anticoagulants, and mitomycin $\mathrm{C}(\mathrm{MMC})$ have been used in order to optimize endoscopic treatment. Mitomycin is a natural antibiotic produced by Streptomyces caespitosus. In 1956, Hata et al. described mitomycin A and B. ${ }^{(5)}$ In 1958, Wakaki et al. described MMC. ${ }^{(6)}$ In addition to being an antibiotic, MMC acts as an antineoplastic or alkylating agent by inhibiting DNA synthesis. It was first used in 1963 by ophthalmologists for pterygium surgery, with excellent results, ${ }^{(7)}$ and it is currently widely used as a topical agent to prevent scar formation following cataract surgery.

The potential effects of MMC on the airways were first studied in 1998 by Ingrams et al. ${ }^{(8)}$ The authors investigated the effect of MMC on paranasal sinus mucosal healing in rabbits and found inhibition of fibroblasts when MMC was used at a concentration of $0.04 \mathrm{mg} / \mathrm{mL}$. ${ }^{(8)}$ Although animal and human studies have examined the use of MMC in the upper and lower airways, there is still uncertainty on this issue because of the heterogeneous nature of human studies and the scarcity of histological specimens in experimental studies. Nevertheless, on the basis of previous studies, MMC came to be used in the endoscopic treatment of lower airway stenosis at our institution in 2003. Therefore, the objective of the present study was to evaluate the efficacy of MMC in the endoscopic treatment of tracheal stenosis. 


\section{METHODS}

This was a prospective cohort study conducted between 2003 and 2010. The study was approved by the local research ethics committee and involved patients who had tracheal stenosis and in whom surgery was not indicated. MMC was handled in accordance with the Brazilian Department of Health Care guidelines. ${ }^{(9)}$

The inclusion criteria were as follows: being bedridden (having been discharged from the ICU but showing incomplete disease resolution); recent acute myocardial infarction; recent stroke (with neurological deficit or a high risk of reintubation); psychiatric disorder not controlled by medications; immature stenosis (with or without a tracheostomy performed within the first 3 months after injury); stenosis with acute inflammation; early or late postoperative restenosis responding well to dilation; membranous stenosis responding well to dilation; and complex stenosis (i.e., stenoses at more than one site or an old stenosis with a Montgomery T-tube in situ). The exclusion criteria were as follows: having indication for surgery at the time of initial evaluation; having a congenital disease or presenting with acute-phase infectious disease such as tuberculosis and blastomycosis; having extensive stenosis not amenable to dilation or without a fibrous ring (malacia); having undergone post-dilation; having no open wound; and presenting with tracheal or tracheobronchial infection.

In order to evaluate the efficacy of MMC, an initial evaluation was performed by rigid bronchoscopy. Subsequently, dilation of the stenotic area was performed and was followed by topical application of MMC at a concentration of $0.5 \mathrm{mg} / \mathrm{mL}$ for $2 \mathrm{~min}, \mathrm{MMC}$ being reapplied for another 2 min immediately after dilation. Patients with a tracheostomy (a Montgomery T-tube in situ) were reevaluated after 1 month, whereas those without a tracheostomy were reevaluated after 2 weeks, MMC being applied again as described above if necessary. Treatment was discontinued in patients with drug-related complications such as tracheal infection and allergy, as well as in those with no response to the first application. In patients who had an incomplete response to MMC but were eligible for surgery, treatment was discontinued and surgery was indicated.

We analyzed the following variables: sex; etiology of stenosis; indication for treatment with MMC; site, length, and percentage of stenosis (as evaluated by bronchoscopy); presence of tracheostomy; and duration of follow-up. We evaluated the following outcomes: resolution (i.e., stenosis of less than $20 \%$ with no symptoms for at least 12 months); number of dilations with topical application of MMC; and complications. Descriptive statistics were calculated, including frequency, proportion, mean, and standard deviation.

\section{RESULTS}

A total of 22 patients met the inclusion criteria, being evaluated in the period between 2003 and 2010. Of those 22 patients, 15 were male and 7 were female.
In addition, 15 received primary treatment with MMC. Stenosis was caused by endotracheal intubation in those patients, 9 of whom had been intubated because of trauma and 6 of whom had been intubated because of complications of acute or chronic disease (Table 1 ).

Of the 22 patients included in the study, 8 received secondary treatment for postoperative stenosis (restenosis at the anastomosis site). Of those 8 patients, 2 had undergone laryngotracheoplasty, 3 had undergone tracheoplasty, and 3 had undergone tracheobronchoplasty (Table 2 ). Of the 3 patients who had undergone tracheoplasty, 1 had received primary treatment with MMC.

There were two cases of stenosis at the tracheobronchial anastomosis site after right main bronchus resection: one was due to leiomyosarcoma, and the other was due to tuberculosis. In addition, there was one case of stenosis at the tracheobronchial anastomosis site after resection for complete occlusion of the left main bronchus, the cause of which was unknown.

Of the 22 patients included in the study, 13 had tracheal stenosis, 4 had subglottic stenosis, 3 had tracheobronchial stenosis, and 2 had complex stenosis. Of those 2 patients, 1 had laryngotracheal stenosis and 1 had stenosis of the larynx and left main bronchus. The length of stenosis ranged from $0.5 \mathrm{~cm}$ to $2.5 \mathrm{~cm}$ (mean, $1.25 \mathrm{~cm}$ ), and the percentage of stenosis ranged from $40 \%$ to $100 \%$ (mean, $76 \%$ ).

Of the sample as a whole, 9 had undergone a tracheostomy procedure and had a Montgomery T-tube in situ. Of those, 4 were in the group of patients with postoperative stenosis and 6 were in that of those with stenosis following endotracheal intubation (meaning that 1 of the 9 patients was in both groups).

Of the 8 patients with postoperative stenosis, 6 (75\%) responded well to treatment and 2 did not. Of those, one had stenosis after left tracheobronchoplasty (a carinal prosthesis therefore being required), and the other had keloid scarring at the anastomosis site, tracheal lumen size having therefore decreased by $50 \%$. Of the 15 patients with stenosis following endotracheal intubation, $8(53 \%)$ responded well to treatment. The number of dilations per patient ranged from 1 to 5 (mean, 2.4).

Complications resulting from MMC use occurred in 1 patient, who had a tracheobronchial infection after the first application. Other complications resulted from dilation (mediastinal emphysema) or surgery (keloid scarring at the anastomosis site). The mean follow-up period was 30 months, ranging from 12 months to 72 months.

\section{DISCUSSION}

Surgical treatment of laryngotracheal stenosis by resection of the stenotic segment followed by endto-end anastomosis has proven effective ${ }^{(10)}$; however, not all patients are amenable to it. It is therefore important to have an effective endoscopic treatment 


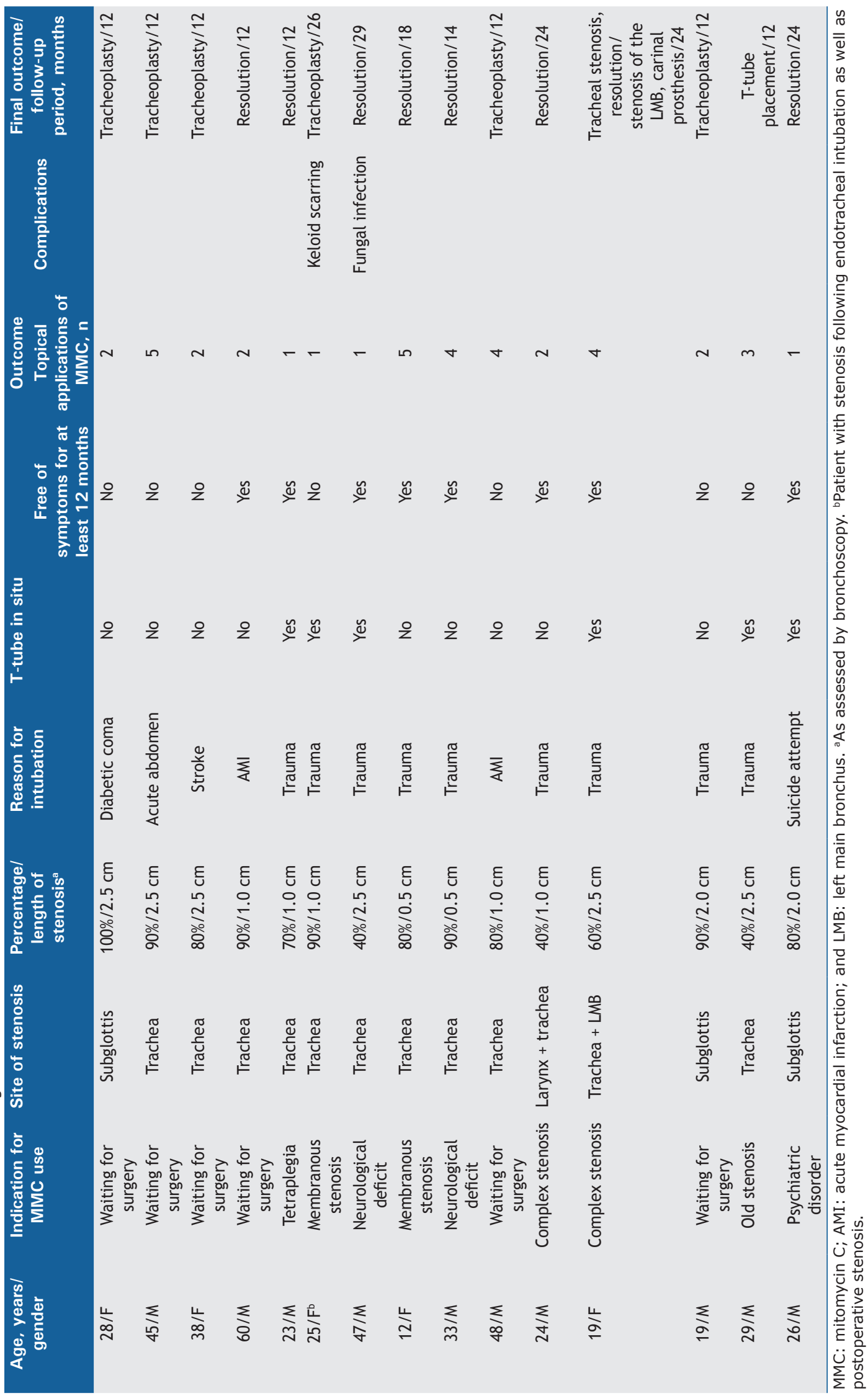




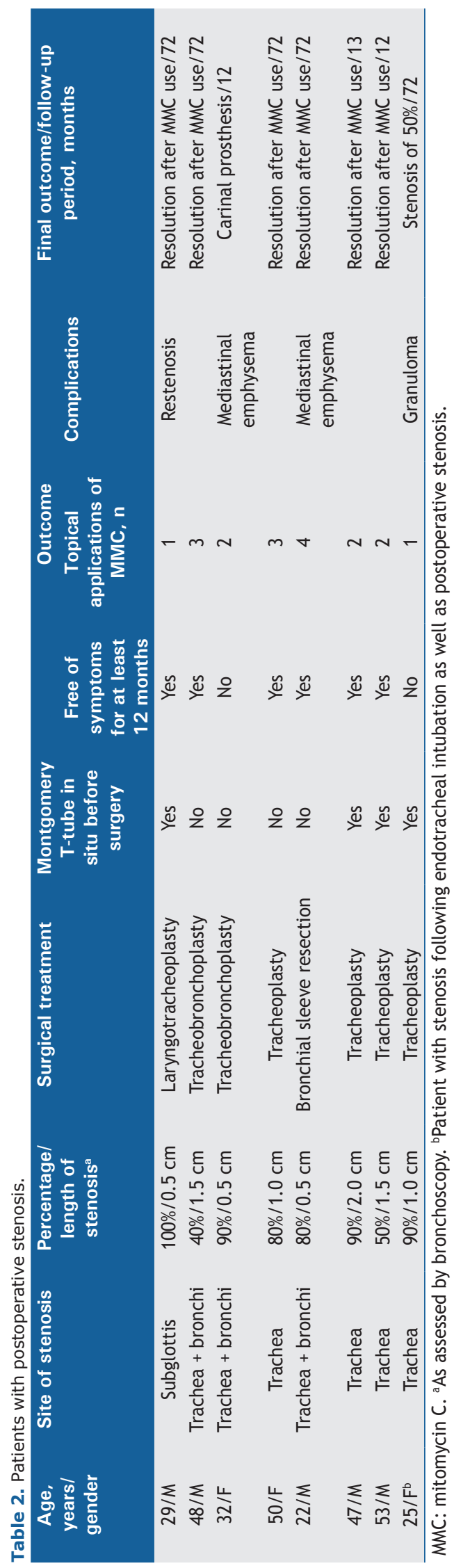

for laryngotracheal stenosis. Endoscopic treatment is based on dilation of the stenotic area; however, wound healing can result in restenosis. Drugs that prevent fibroblast proliferation can slow down or even inhibit this process.

MMC was first used in the airways in the late 20th century, and, since then, few studies have demonstrated its efficacy ${ }_{r}^{(11,12)}$ whereas others have shown it to be ineffective. ${ }^{(13)}$ Although there has been an increase in the number of cases of laryngotracheal stenosis-an increase that is probably due to the success of intensive care medicine-the prevalence of laryngotracheal stenosis is still low; however, there has been an increase in the number of cases of complex stenosis. ${ }^{(14)}$ Our study demonstrates that dilation with topical application of $M M C$ is effective in maintaining airway patency, the probability of resolution, characterized by a symptomfree interval $\geq 12$ months, being approximately $60 \%$. Although we did not compare dilation alone and dilation with topical application of MMC in the present study, retrospective studies have shown that the latter method yields better results. ${ }^{(15-17)}$

The present study shows that ICU patients can be safely discharged from the ICU and wait for surgery without a tracheostomy if the hospital has a respiratory endoscopy department where dilation and topical application of MMC can be performed. None of the 6 patients who were waiting for surgery required a tracheostomy, dilations and topical applications of MMC being sufficient to maintain airway patency. Another advantage is that dilation with topical application of MMC can result in resolution of tracheal stenosis without surgical intervention. Four of our patients with neurological or psychiatric disorders achieved complete resolution without a more invasive procedure, reintubation sometimes being required in such patients because of their underlying disease. Reduced hospital costs constitute yet another advantage of endoscopic treatment. One of our patients who were waiting for surgery achieved complete resolution of stenosis after endoscopic treatment. It has been reported that endoscopic treatment with topical application of MMC is cost-effective if 1 of 17 patients requires one less operation. ${ }^{(18)}$ Endoscopic treatment with topical application of MMC costs US\$ 455.00 per patient, whereas open surgery costs US $\$ 7,840.00$, meaning that the latter is 17 times more expensive than the former. Although these data are not directly comparable between the two countries (i.e., the USA and Brazil), surgical treatment is much more costly than endoscopic treatment with MMC in Brazil as well.

Previous studies have shown that MMC appears to be effective in the treatment of postoperative stenosis. ${ }^{(19)}$ Of the 8 patients with postoperative stenosis in the present study, only 2 had no resolution, the reasons being idiopathic bronchial stenosis (in 1) and keloid scarring (in 1).

Despite the advantages of using MMC in the endoscopic treatment of tracheal stenosis, several issues require further investigation. In our study, there were two 
cases of complex stenosis (i.e., stenoses at more than one site), and only one responded to treatment. In addition, there were two cases of membranous stenosis. Although we expected that they would be easily resolved by endoscopic treatment with topical application of MMC, 1 patient did not respond to treatment, tracheoplasty therefore being required.

There is no consensus in the literature regarding the number of procedures required. In a randomized, prospective, double-blind, placebo-controlled clinical trial, ${ }^{(20)}$ two applications of MMC were found to be more effective than only one in the endoscopic management of laryngotracheal stenosis.

Airway obstruction is the major complication caused by MMC and its local toxicity. Although there were no cases of airway obstruction in the present study, there was one case of rapid accumulation of fibrinous debris at the surgical site, resulting in partial airway obstruction, as described elsewhere. (21) The only MMCrelated complication identified in the present study was fungal infection, emphysema and hypertrophic scarring being attributed to dilation and individual predisposition, respectively.

Although treatment with MMC led to stenosis resolution in little more than half of the cases in the present study, $\mathrm{MMC}$ was found to be effective when used in combination with tracheal dilation for the treatment of postoperative stenosis and stenosis following endotracheal intubation. In cases of stenosis following endotracheal intubation, MMC is effective in maintaining airway patency without the need for a prosthesis or a tracheostomy, leading to complete resolution of stenosis or maintaining lumen patency until patients can be operated on. Therefore, topical application of MMC is a treatment option for patients who cannot undergo surgery and those with post-surgical restenosis.

\section{REFERENCES}

1. MacEwen W. Clinical Observations on the Introduction of Tracheal Tubes by the Mouth Instead of Performing Tracheotomy or Laryngotomy. Br Med J. 1880;2:122-4. https://doi.org/10.1136/ bmj.2.1021.122

2. Colles CJI. On Stenosis of the Trachea after Tracheotomy for Croup and Diphtheria. Ann Surg. 1886;3(6):499-507

3. Parker NP, Bandyopadhyay D, Misono S, Goding GS Jr. Endoscopic cold incision, balloon dilation, mitomycin C application, and steroid injection for adult laryngotracheal stenosis. Laryngoscope. 2013;123(1):220-5. https://doi.org/10.1002/lary.23638

4. Viveiros F, Gomes J, Oliveira A, Neves S, Almeida J, Moura Sá J. Topical application of mitomycin-C as an adjuvant treatment to bronchoscopic procedures in post-intubation tracheal stenosis. Rev Port Pneumol. 2013;19(6):276-80. https://doi.org/10.1016/j. rppneu.2013.06.006

5. Hata T, Sano Y, Sugawara R, Matsumae A, Sano Y, Shima T, et al Mitomycin, a new antibiotic from Streptomyces I. J Antibiot (Tokyo) 1956;9(4):141-6

6. Wakaki S, Marumo H, Tomioka K, Shimizu G, Kato E, Kamada H, et al. Isolation of new fractions of antitumor mitomycins. Antibiot Chemother (Northfield). 1958;8(5):228-40.

7. Kunitomo N, Mori S. Studies on pterygium. Part 4. A treatment of the pterygium by mitomycin C instillation. Acta Soc Ophthalmol Jpn. 1963;67:601-7.

8. Ingrams DR, Volk MS, Biesman BS, Pankratov MM, Shapshay SM Sinus surgery: does mitomycin $C$ reduce stenosis? Laryngoscope. 1998;108(6):883-6. https://doi.org/10.1097/00005537-19980600000017

9. Brasil. Ministério da Saúde. Instituto Nacional de Câncer José Alencar Gomes da Silva (INCA) [homepage on the Internet]. Rio de Janeiro: INCA [cited 2017 Oct 1]. Manual de boas práticas. Exposição ao risco químico na central de quimioterapia: conceitos e deveres. 2015 http://www1.inca.gov.br/inca/Arquivos/manual_quimioterapia_2015. pdf

10. Grillo HC, Donahue DM, Mathisen DJ, Wain JC, Wright CD Postintubation tracheal stenosis. Treatment and results. J Thorac Cardiovasc Surg. 1995;109(3):486-92; discussion 492-3. https://doi. org/10.1016/S0022-5223(95)70279-2

11. Correa AJ, Reinisch L, Sanders DL, Huang S, Deriso W, Duncavage $\mathrm{JA}$, et al. Inhibition of subglottic stenosis with mitomycin-C in the canine model. Ann Otol Rhinol Laryngol. 1999;108(11 Pt 1):1053-60.
12. Spector JE, Werkhaven JA, Spector NC, Huang S, Page RN, BaranowskiB, etal. Preservation of function and histologic appearance in the injured glottis with topical mitomycin-C. Laryngoscope. 1999;109(7 Pt 1):1125-9. https://doi.org/10.1097/00005537199907000-00022

13. Madan K, Agarwal R, Aggarwal AN, Gupta D. Utility of rigid bronchoscopic dilatation and mitomycin C application in the management of post intubation tracheal stenosis: case series and systematic review of literature. J Bronchology Interv Pulmonol. 2012;19(4):304-10. https://doi.org/10.1097/LBR.0b013e3182721290

14. Nouraei SA, Ma E, Patel A, Howard DJ, Sandhu GS. Estimating the population incidence of adult post-intubation laryngotrachea stenosis. Clin Otolaryngol. 2007; 32(5):411-2. https://doi.org/10.1111/ j.1749-4486.2007.01484.x

15. Perepelitsyn I, Shapshay SM. Endoscopic treatment of laryngeal and tracheal stenosis-has mitomycin C improve the outcome? Otolaryngol Head Neck Surg. 2004;131(1):16-20. https://doi. org/10.1016/j.otohns.2004.03.001

16. Simpson CB, James JC. The efficacy of mitomycin-C in the treatment of laryngotracheal stenosis. Laryngoscope. 2006;116(10):1923-5. https://doi.org/10.1097/01.mlg.0000235934.27964.88

17. Reichert LK, Zhao AS, Galati LT, Shapshay SM. The Efficacy of Mitomycin C in the Treatment of Laryngotracheal Stenosis: Results and Experiences with a Difficult Disease Entity. ORL J Otorhinolaryngol Relat Spec. 2015;77(6):351-8. https://doi. org/10.1159/000439174

18. Ubell ML, Ettema SL, Toohill RJ, Simpson CB, Merati AL. Mitomycin-c application in airway stenosis surgery: analysis of safety and costs. Otolaryngol Head Neck Surg. 2006;134(3):403-6. https:// doi.org/10.1016/j.otohns.2005.10.057

19. Hartnick CJ, Hartley BE, Lacy PD, Liu J, Bean JA, Willging JP, et al. Topical mitomycin application after laryngotracheal reconstruction: a randomized, double-blind, placebo-controlled trial. Arch Otolaryngo Head Neck Surg. 2001;127(10):1260-4. https://doi.org/10.1001/ archotol.127.10.1260

20. Smith ME, Elstad M. Mitomycin C and the endoscopic treatment of laryngotracheal stenosis: are two applications better than one? Laryngoscope. 2009;119(2):272-83. https://doi.org/10.1002/ lary.20056

21. Hueman EM, Simpson CB. Airway complications from topica mitomycin C. Otolaryngol Head Neck Surg. 2005;133(6):831-5. https://doi.org/10.1016/j.otohns.2005.07.031 